\title{
A Simulated Climatology of Spectrally Decomposed Atmospheric Infrared Radiation
}

\author{
YI HUANG \\ Department of Atmospheric and Oceanic Sciences, McGill University, Montreal, Quebec, Canada
}

(Manuscript received 13 July 2012, in final form 31 August 2012)

\begin{abstract}
A simulation experiment is conducted to inquire into the mean climate state and likely trends in atmospheric infrared radiation spectra. Upwelling and downwelling spectra at five vertical levels from the surface to the top of the atmosphere (TOA) are rigorously calculated from a climate-model-simulated atmosphere for a 25 -yr period. Tracing the longwave radiation flux vertically and spectrally renders a dissection of the greenhouse effect of the earth atmosphere and its change due to climate forcings and feedbacks. The results show that the total outgoing longwave radiation (OLR) at the TOA may be conserved due to 1) compensating temperature and opacity effects and 2) contrasting temperature changes in troposphere and stratosphere. The tightly coupled tropospheric temperature and opacity effects reduce the overall tropospheric contribution to OLR change to be comparable to the overall stratospheric contribution, which suggests that transient OLR change is constrained by the relative strengths of stratospheric and tropospheric temperature changes.

The total OLR energy, however, is redistributed across its spectrum. The earliest detectable global climate change signal lies in the $\mathrm{CO}_{2}$ absorption bands, which results from stratospheric cooling and the $\mathrm{CO}_{2}$ opacity effect. This signal can be detected much sooner than surface temperature change and is little affected by achievable instrument accuracy.

In contrast, both tropospheric temperature and opacity effects increase downwelling longwave radiation (DLR), which makes DLR a verifiable aspect of global warming. The time it takes to detect surface DLR change roughly equals that of surface temperature change. Measuring downwelling radiances at strong water vapor lines at the tropopause can particularly help monitor stratospheric water vapor.
\end{abstract}

\section{Introduction}

When thermal infrared (IR) radiation (often termed longwave radiation, in comparison to the solar radiation of shorter wavelength) emitted by the earth's surface is transmitted through the atmosphere, it is absorbed by greenhouse gases such as water vapor, carbon dioxide, ozone, etc., as well as by clouds. The atmosphere radiates thermal emission back to the surface in return and thus maintains a much higher surface temperature than otherwise (if the atmosphere did not exist). This basically is the greenhouse effect of the earth atmosphere. The atmosphere also radiates to outer space. The atmospheric emission together with the surface emission that transfers through the atmosphere constitutes the outgoing longwave radiation (OLR) that balances the net incoming solar radiation at the top of the atmosphere (TOA). This balance is a necessary condition for

Corresponding author address: Yi Huang, 805 Sherbrooke Street West, Montreal QC H3Z 0B9, Canada.

E-mail: yi.huang@mcgill.ca the climate system to maintain a steady thermal state. In a global annual-mean sense, radiation energy flux that can be conceptualized to vertically transfer through the atmosphere is an essential part of the energy budget of the earth climate system (Kiehl and Trenberth 1997). The importance of the total energy fluxes at the two boundaries of the atmosphere-at the TOA and at the earth's surface-is widely recognized. While the TOA radiation energy budget exerts an overall constraint on whether the system gains or loses energy, the surface radiation fluxes are tied to the vertical sensible and latent heat transports: the latter of which essentially governs the global mean precipitation and, thus, the hydrological cycle. Although rigorously computed by climate models in order to obtain heating rate profiles, the vertical distribution of the radiation fluxes themselves are usually analyzed to a lesser extent. This is partly due to the lack of global observational constraints despite their importance.

The rich information content borne in atmospheric infrared radiation spectra is evident from the TOA OLR and the surface downwelling longwave radiation (DLR) 
spectra, which are monitored by satellites [e.g., the Atmospheric Infrared Sounder (AIRS)] and ground instruments [e.g., the Atmospheric Emitted Radiance Interferometer (AERI)], respectively, and have been extensively used for retrieving atmospheric thermal and compositional structures. Besides the spectrum-byspectrum retrieval of the atmospheric states, it has been recognized that the radiative forcings and feedbacks of the global climate system can be distinguished and separately quantified by their spectral signatures in OLR (Harries et al. 2001; Leroy et al. 2008; Huang et al. 2010a,b), and thus satellite spectral measurements provide an advantageous means for monitoring and attributing climate changes. With regard to DLR spectrum measured on the ground, Gero and Turner (2011) recently showed that regional climate changes are disclosed by multiyear AERI data. However, much less is recorded or analyzed with regard to the radiation spectra distributed within the atmosphere. Whether and how height-dependent spectral information, which can be measured by balloon- or aircraftborne instruments [e.g., the Scanning High-Resolution Interferometer Sounder (S-HIS) and the Far-Infrared Spectroscopy of the Troposphere (FIRST) both have participated various campaigns] may help monitor and provide understanding of atmospheric state changes is a question worth addressing. Hence, in addition to great academic interest, there are also practical reasons to assess the climatological states and likely changes of the vertically distributed and spectrally decomposed atmospheric radiation.

Because extensive spectral measurement data have yet to become available, this assessment relies on synthetic data computed by a spectral radiation code from a virtual atmosphere simulated by a general circulation model (GCM). This work essentially is an observing system simulation experiment (OSSE), a concept that has been broadly used in weather prediction assessments and recently also applied to long-term, large-scale climate variability and trend-oriented observational diagnosis and mission planning, particularly with regard to hyperspectral data (Huang and Ramaswamy 2009; Feldman et al. 2011). On the one hand, in model-satellite comparisons, such methodology ensures consistent sampling of the atmosphere when a specific instrument is borne in mind and avoids the uncertainties associated with retrievals. On the other hand, OSSE provides a most comprehensive tool for verifying the concept of and assessing the limitations of yet-to-launch observing programs.

Owing to the great computational cost of spectral simulation, various sampling approximations have been taken in previous OSSEs. For instance, Huang and
Ramaswamy (2009) adopted a sampling scheme that mimics a sun-synchronous polar orbital satellite, which reduces the computation to about $5 \%$ of all instantaneous atmospheric profiles generated by the GCM; the simulations of Huang et al. (2010 a,b) and Feldman et al. (2011) were based on monthly mean profiles (computation reduced by 240 -fold). Kato et al. (2011a) noted the importance of temporal resolution for appropriately reproducing the OLR spectral changes. Without an experiment that fully samples the atmospheric spectra, possible impacts of these subsampling approximations on the conclusions with regard to the detectability and attributability of spectral climate change signals cannot be assessed. Hence, besides the reasons raised above, we are motivated to conduct a rigorous OSSE and assess the climatology and variability of the atmospheric radiation spectra computed from all instantaneous spectra generated in every GCM grid box and at every time step.

The paper is structured as follows. The next section describes the OSSE experiment. This is followed by the climatology of height-dependent broadband and spectral irradiances at five different atmospheric levels: surface, $700 \mathrm{hPa}, 400 \mathrm{hPa}, 100 \mathrm{hPa}$, and TOA. Then the likely secular trend signals in the spectral time series, compared to uncertainties mainly arising from the natural variabilities and instrument inaccuracy, will be analyzed. The paper concludes with a summary of the indications of this theoretical experiment.

\section{The OSSE}

We use an observing system simulation experiment to inquire into the global climatology of and the likely trends in the atmospheric infrared radiation spectra. Because observational records of atmospheric states are subject to discontinuity and artifacts due to the changes in instrumentation, a GCM-simulated atmosphere is chosen for generating our synthetic radiation spectra. The rationale is to use the modeled, ideal atmosphere to understand the basic climate features of radiation spectra in relation to conventional geophysical variables (temperature, water vapor, cloud properties, etc.). What is learned will provide guidance for instruments designed to capture specific climate change signals of interest and can be used as prior knowledge to aid the analysis of actual data when they become available. Synthetic data are also useful as they often complement actual data that are subject to instrumentation and sampling issues. It is especially beneficial to combine both data types in climate diagnosis. For instance, the study of Huang and Ramaswamy (2008) shows how the cause of the so-called super greenhouse effect can be diagnosed by combining observed and simulated OLR spectral data. 
Because the radiation codes embedded in climate models do not have the spectral resolution that is desired for our experiment, an offline radiation code, Moderate Resolution Atmospheric Transmission (MODTRAN) version 4, is integrated with a GCM, the Geophysical Fluid Dynamics Laboratory coupled atmosphere-ocean model, version 2 (CM2), in order to simulate the spectra of upwelling and downwelling radiation at the aforementioned five vertical levels. Following Huang and Ramaswamy (2009), the atmospheric profiles including surface conditions from a 25 -yr period (1980-2004) generated by the CM2 are fed, offline, to MODTRAN to simulate the transmission functions at $1 \mathrm{~cm}^{-1}$ spectral resolution under both clear and cloudy skies. The transmission functions are then used to compute upwelling and downwelling radiance spectra at different vertical levels and at different zenith angles, according to an appropriate cloud-overlapping scheme. Here the random-overlapping scheme is adopted to be consistent with CM2's own radiation codes. The surface is assumed to be blackbody. Radiance spectra are simulated at the nadir and a reference zenith angle, at which irradiance is calculated via the diffusivity approximation. The consistency between regenerated radiation spectra in this OSSE with the original (online) CM2 simulation is verified by comparing the spectrally integrated OLR values. As validated by Huang et al. (2007) and Huang and Ramaswamy (2009), there is no substantial bias between offline and online simulated OLRs. So, the presentation below will be based on the offline OSSE results only. For the spectra in particular, we will focus on the spectral range from 10 to $2200 \mathrm{~cm}^{-1}$.

The formulation and simulation characteristics of the CM2 are documented by Delworth et al. (2006). The atmospheric component of this model has 24 vertical levels and a horizontal resolution of $2.5^{\circ}$ longitude by about $2^{\circ}$ latitude. Its vertical coordinate is a hybrid one: 18 sigma-pressure levels in the troposphere and six fixed pressure levels below $200 \mathrm{hPa}$. The CM2 simulation results used here are taken from the Climate of the 20th Century experiment but extended to year 2004. Radiative forcings prescribed in the $\mathrm{CM} 2$ integration include well-mixed greenhouse gases $\left(\mathrm{CO}_{2}, \mathrm{CH}_{4}, \mathrm{~N}_{2} \mathrm{O}\right.$, and $\mathrm{CFCs}$ ), ozone, and aerosols. The well-mixed greenhouse gas concentrations are taken from the documented historical global mean values; the concentrations of variable species such as ozone and aerosols are offline simulated by a chemistry-transport model and then prescribed to the $\mathrm{CM} 2$ integration as a function of space and time. Note that this period includes two very strong volcanic eruptions (El Chichón in 1982 and Mt. Pinatubo in 1991) that have global impacts on atmospheric compositional and thermal structures. To ensure consistency with the $\mathrm{CM} 2$ radiative computation, the same time-dependent greenhouse gas concentrations are fed into MODTRAN to compute the radiance spectra. The spectra are computed in every grid box every three hours: the same frequency at which CM2 updates its radiation fields. The spectral results reported below are all based on spatial and temporal averages of such 3-h "instantaneous" results.

The CM2 version adopted here for the OSSE is CM2.1, which has a moderately above-average climate sensitivity among the phase 3 of the Coupled Model Intercomparison Project (CMIP3) models submitted to the last Intergovernmental Panel on Climate Change report (Solomon et al. 2007). The evolution of the atmospheric states during the $25-\mathrm{yr}$ CM2 simulation period used here was already documented by Huang and Ramaswamy (2009); the time series and trends in the atmospheric profiles of two key variables-temperature and water vapor specific humidity-are reproduced in Fig. 1. Here, the linear trends and associated uncertainty are calculated with the formula of Weatherhead et al. (1998), which takes into account autoregression in the time series. To recap, during this period CM2 simulates a substantial increase in global annual-mean surface and tropospheric temperatures and also a substantial cooling in the stratosphere $(+0.2 \mathrm{~K}$ per decade warming at surface and $-0.7 \mathrm{~K}$ cooling at $50 \mathrm{hPa}$ ). Meanwhile, as the troposphere gets moister, a consequence of the warming due to the thermodynamical constraint, the stratosphere interestingly also gets moister despite the cooling.

Among the CMIP3 models, CM2 has one of most credible climatology and historical trend simulations compared to observations (Solomon et al. 2007). Huang et al. (2007) showed that the OLR spectra simulated from the atmospheric component, AM2, of this coupled model reasonably reproduce the satellite (AIRS) observations in terms of global and regional annual means. Huang and Ramaswamy (2009) further showed that the seasonal and interannual variabilities of the OLR spectra simulated from this CM2 integration agree very well with the satellite observations. These comparison tests show evidence that the synthetic spectra at other atmospheric levels are likely good representations of those resulting from the true atmosphere as well. Hence, we simulate and present below the climatology of spectrally integrated and decomposed longwave irradiance at five vertical levels: surface, $700 \mathrm{hPa}, 400 \mathrm{hPa}$, $100 \mathrm{hPa}$, and TOA. The atmospheric layers bounded by these vertical levels are termed lower troposphere, middle troposphere, upper troposphere, and stratosphere, respectively. 

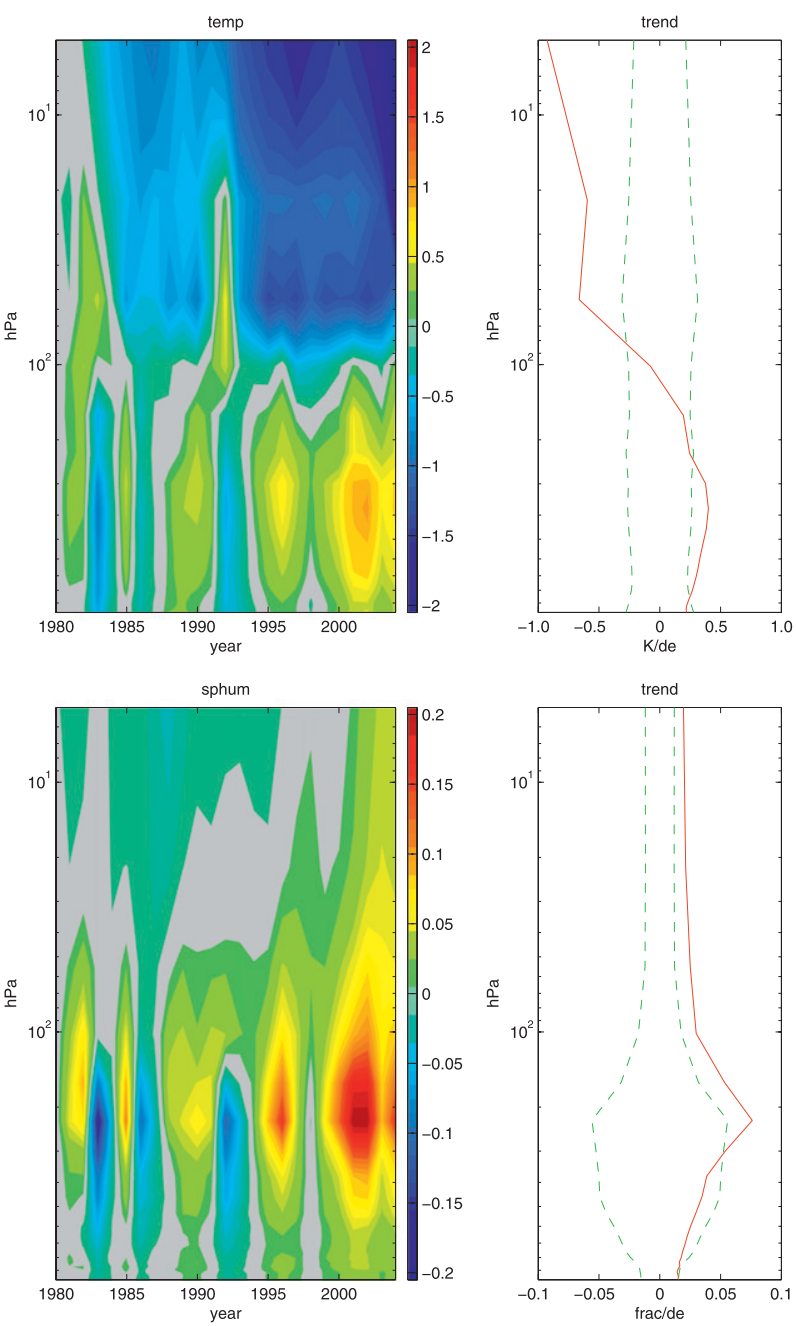

FIG. 1. Global annual-mean (top) atmospheric temperature (K) and (bottom) specific humidity (dimensionless) (left) anomaly time series and (right) linear trends. The anomaly is calculated with respect to 1980 values. Compared to the trends in red are the uncertainty envelop in green.

\section{Climatology}

\section{a. Simulation results}

The global 25-yr mean spectrally integrated irradiances simulated at the five levels are tabulated in
Table 1. Figures 2 and 3 illustrate the spatial and spectral breakdown of global-mean fluxes at the five vertical levels.

From the upwelling and downwelling longwave radiation fluxes (denoted as $R^{+}$and $R^{-}$, respectively), the net flux and the vertical divergence of the net flux can be derived. The net flux at each level is defined as

$$
\mathrm{NET}_{i}=R_{i}^{+}-R_{i}^{-} .
$$

Here $i$ is vertical index, increasing from bottom up. Layer $i$ is bounded by levels $i-1$ and $i$. The divergence of the net flux that renders the longwave cooling of the atmospheric layers is calculated as

$$
\mathrm{DIV}_{i}=\mathrm{NET}_{i}-\mathrm{NET}_{i-1} .
$$

The greenhouse effect (GHE) of different vertical portions of the atmosphere can be conceptualized by subtracting the fluxes at consecutive levels. With the aid of the clear-sky irradiance values and spectral breakdown of the flux, the GHE is further attributed to greenhouse gases and clouds. For a greenhouse gas in the $i$ th vertical layer, its GHE on the OLR can be measured by the clearsky OLR difference (in its absorption bands) between the lower and upper boundaries of this layer:

$$
G_{i}^{+}=R_{\mathrm{clr}, i}^{+}-R_{\mathrm{clr}, i+1}^{+} \text {. }
$$

Here $R$ denotes irradiance spectrally integrated over a certain spectral range (see spectral band definition in Table 2); "clr" denotes clear sky and "all," all sky.

The greenhouse effect of clouds can be assessed by "cloud forcing," which is defined as the difference between clear- and all-sky OLR at the TOA:

$$
C^{+}=R_{\text {clr,toa }}^{+}-R_{\text {all,toa }}^{+} \cdot
$$

The GHE and cloud forcing for the DLR can be formalized analogously:

$$
G_{i}^{-}=R_{\mathrm{clr}, i}^{-}-R_{\mathrm{clr}, i+1}^{-}
$$

\begin{tabular}{|c|c|c|c|c|c|c|c|c|}
\hline & $R^{+}$ & $R^{-}$ & NET & DIV & $R_{\text {clear }}^{+}$ & $R_{\text {clear }}^{-}$ & $\mathrm{NET}_{\text {clear }}$ & DIV $_{\text {clear }}$ \\
\hline Surface & 396.3 & 334.0 & 62.3 & & 396.3 & 305.6 & 90.7 & \\
\hline $700 \mathrm{hPa}$ & 340.5 & 210.7 & 129.8 & 67.5 & 347.7 & 192.6 & 155.1 & 64.5 \\
\hline $400 \mathrm{hPa}$ & 284.2 & 90.4 & 193.8 & 63.9 & 298.0 & 81.2 & 216.8 & 61.7 \\
\hline $100 \mathrm{hPa}$ & 243.3 & 17.0 & 226.3 & 32.5 & 265.4 & 16.9 & 248.5 & 31.7 \\
\hline TOA & 240.2 & 0.0 & 240.2 & 13.9 & 260.9 & 0.0 & 260.9 & 12.4 \\
\hline Total & & & & 177.9 & & & & 170.2 \\
\hline
\end{tabular}

TABLE 1. Global multiyear-mean upwelling and downwelling radiation fluxes $\left(\mathrm{W} \mathrm{m}{ }^{-2}\right.$ ) (denoted as $R^{+}$and $R^{-}$, respectively), net longwave radiation (NET), and divergence (DIV) of the longwave radiation at five vertical levels. Clear-sky values are denoted by subscript "clear". 


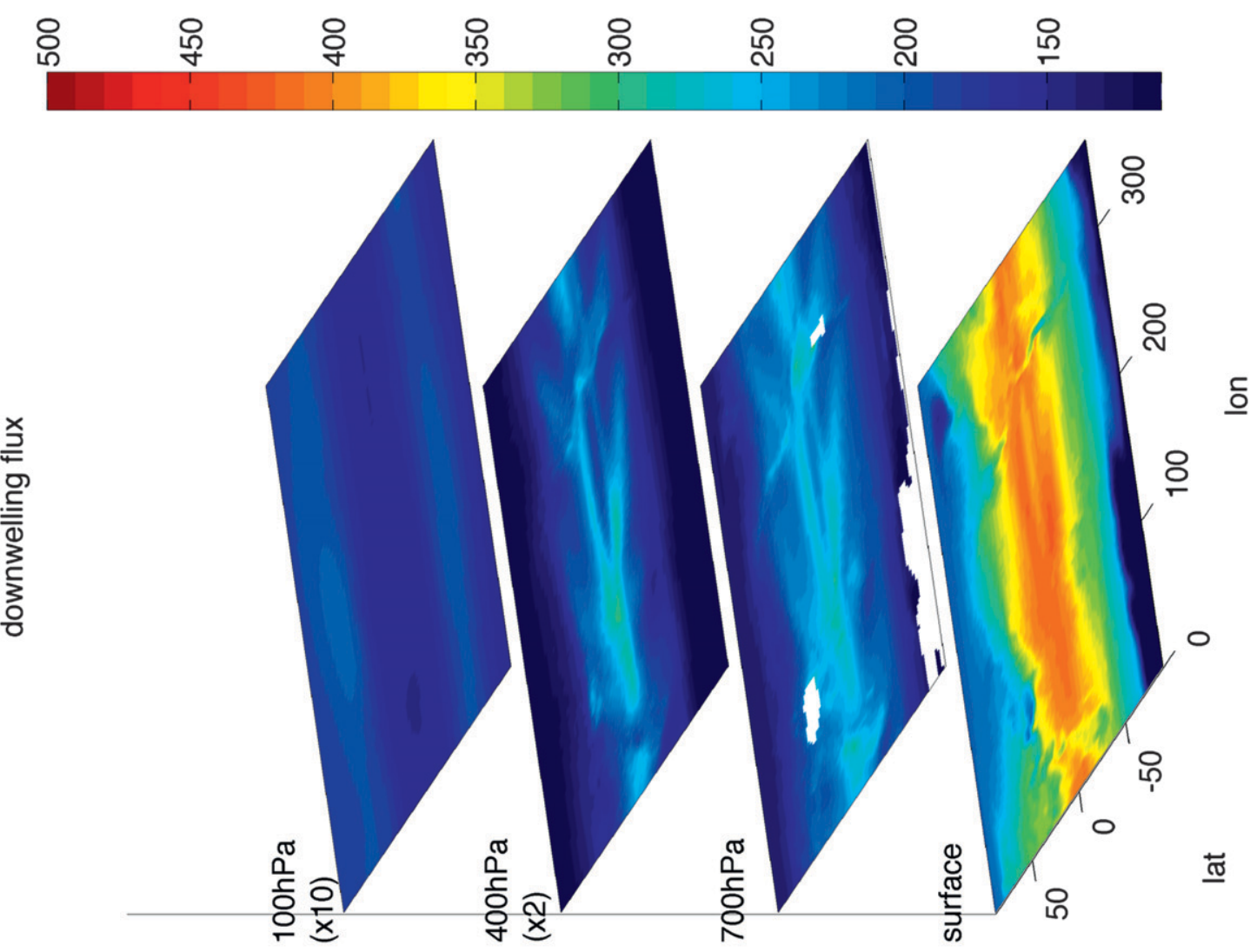

용

일
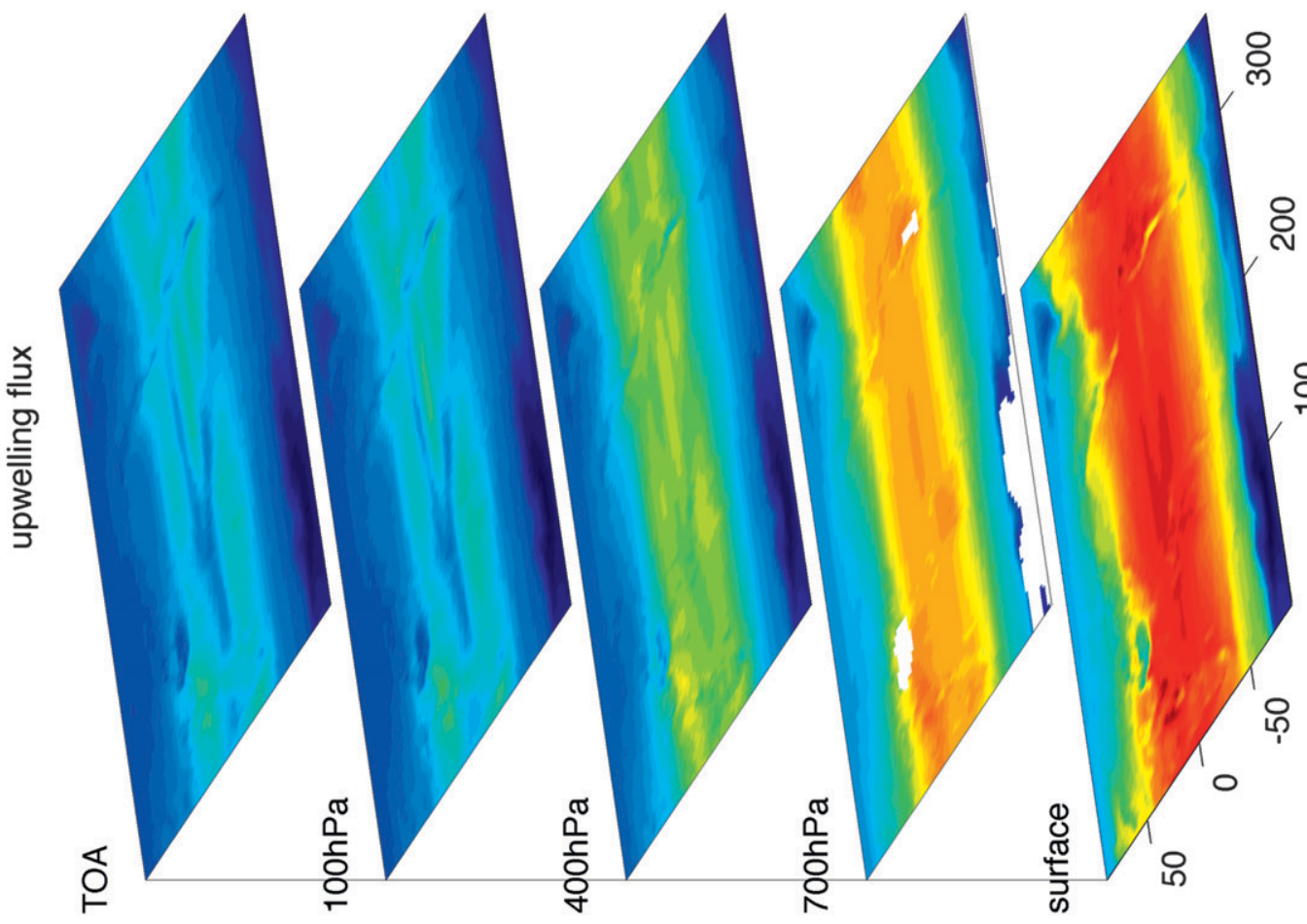

으

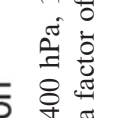

胥定

过

₹.

๑ే छ

节 す

a

웡

를

20응

焉离

范

항

呵

这

드

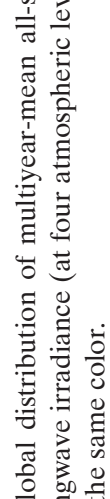

우

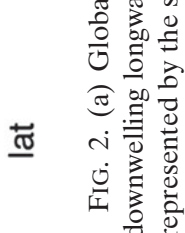




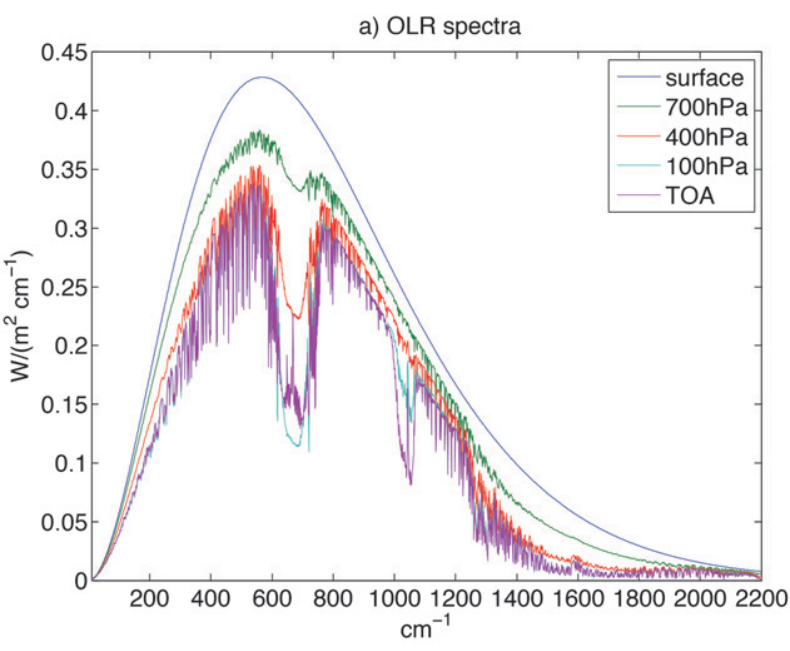

b) DLR spectra

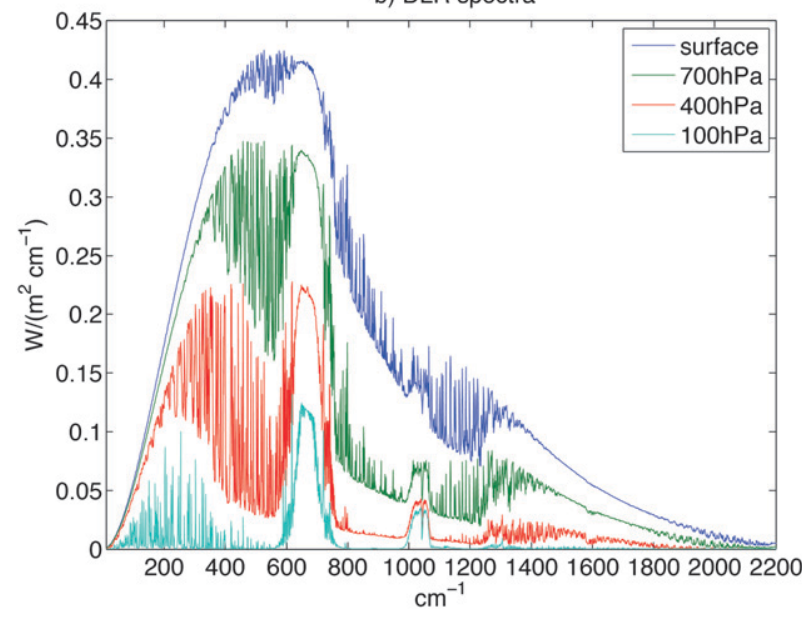

FIG. 3. Spectrally decomposed global multiyear-mean (a) upwelling and (b) downwelling longwave radiation.

$$
C^{-}=R_{\mathrm{all}, \mathrm{sfc}}^{-}-R_{\mathrm{clr}, \mathrm{sfc}}^{-} .
$$

Tables 2 and 3 summarize the global mean GHE by different portions of the atmospheric column with respect to the trapping of the OLR and contribution to the DLR, respectively. The greenhouse effect defined above breaks down the overall GHE of the whole atmospheric column (including clouds) into layer-by-layer gas contributions and an overall cloud contribution. A favorable feature of this definition is that the attributions can be linearly added to recover the boundary fluxes. For instance, if one starts with upwelling surface emission, adding $G_{i}^{+}$in each layer and then $C^{+}$will recover the TOA all-sky OLR. It may appear tempting to estimate layerwise GHE of clouds by the difference in the cloud forcings at the layer boundaries: for example, $C_{i}^{+}=\left(R_{\mathrm{cr}, i}^{+}-R_{\mathrm{all}, i}^{+}\right)-\left(R_{\mathrm{cr}, i+1}^{+}-R_{\mathrm{all}, i+1}^{+}\right)$. However, such a measurement would be subject to caveats. When the
TABLE 2. Spectral and vertical breakdown of the greenhouse effect on the outgoing longwave radiation $\left(\mathrm{W} \mathrm{m}^{-2}\right)$. Cloud contribution is assessed by cloud forcing (clear-sky minus all-sky irradiance), while the contributions of the gases are estimated by spectral decomposition of the clear-sky irradiance difference between two consecutive levels. The $\mathrm{H}_{2} \mathrm{O}$ band designates the spectral intervals below $560 \mathrm{~cm}^{-1}$ (the rotational band) and 1350-2200 $\mathrm{cm}^{-1}$ (the vibration-rotational band); $\mathrm{CO}_{2} 560-800 \mathrm{~cm}^{-1}, \mathrm{O}_{3} 990$ $1070 \mathrm{~cm}^{-1} ; \mathrm{CH}_{4} 1250-1350 \mathrm{~cm}^{-1}$; the window 800-990 and 1070$1250 \mathrm{~cm}^{-1}$ (water vapor continuum absorption).

\begin{tabular}{lcrrrrr}
\hline & Window & $\mathrm{H}_{2} \mathrm{O}$ & $\mathrm{CO}_{2}$ & $\mathrm{O}_{3}$ & $\mathrm{CH}_{4}$ & Total \\
\hline Lower troposphere & 4.4 & 27.1 & 13.4 & 0.7 & 2.9 & 48.6 \\
Midtroposphere & 2.8 & 26.9 & 16.6 & 0.8 & 2.6 & 49.7 \\
Upper troposphere & 0.8 & 12.8 & 15.2 & 1.9 & 1.9 & 32.6 \\
Stratosphere & 0.7 & 0.2 & -1.2 & 4.5 & 0.3 & 4.5 \\
Whole column & 8.8 & 66.9 & 44.1 & 7.9 & 7.8 & 135.4 \\
Cloud & 12.3 & 3.4 & 3.1 & 1.5 & 0.5 & 20.7 \\
Column + cloud & 21.1 & 70.3 & 47.1 & 9.3 & 8.3 & 156.1 \\
\hline
\end{tabular}

clear-sky and all-sky incident irradiances $\left(R_{\mathrm{clr}, i+1}^{+}\right.$and $R_{\mathrm{all}, i+1}^{+}$) are not equal (except at the TOA for DLR or at the surface for OLR), the quantity is not only dependent on the radiative effect of the cloud within the layer but the $G$ and $C$ in the preceding layers.

Tables 2 and 3 reiterate some well-known facts: for example, water vapor is the most important greenhouse gas (a greenhouse effect of $66.9 \mathrm{~W} \mathrm{~m}^{-2}$ on OLR and $166.3 \mathrm{~W} \mathrm{~m}^{-2}$ on DLR), followed by $\mathrm{CO}_{2}$ (44.1 and $87.2 \mathrm{~W} \mathrm{~m}^{-2}$, respectively). Interestingly, if comparing the GHE on OLR to that on DLR, the GHEs of two gases scale with the total GHEs but clouds have a relatively larger fractional contribution to the GHE on OLR (20.7 out of $156.1 \mathrm{~W} \mathrm{~m}^{-2}$ ) than that on DLR (28.4 out of $334.0 \mathrm{~W} \mathrm{~m}^{-2}$ ). It is also interesting to notice that in Fig. 4a), the abundant moisture and deep convective clouds in the intertropical convergence zone (ITCZ) leave a strong impact on the upwelling radiation throughout the troposphere. The strong trapping of OLR by water vapor and clouds turns the upwelling radiation in the ITCZ regions from a maximum at the surface (due to higher surface temperature) to a minimum at the TOA (see Fig. 2). In contrast, for the downwelling radiation (Fig. 4b), the ITCZ signature only appears in the GHE of

TABLE 3. Spectral and vertical breakdown of the greenhouse effect on the downwelling longwave radiation $\left(\mathrm{W} \mathrm{m}^{-2}\right)$.

\begin{tabular}{lcrrrrr}
\hline \hline & Window & $\mathrm{H}_{2} \mathrm{O}$ & $\mathrm{CO}_{2}$ & $\mathrm{O}_{3}$ & $\mathrm{CH}_{4}$ & Total \\
\hline Lower troposphere & 27.7 & 45.7 & 29.8 & 4.2 & 5.7 & 113.0 \\
Mid troposphere & 5.4 & 70.6 & 30.2 & 0.9 & 4.3 & 111.4 \\
Upper troposphere & 0.4 & 46.2 & 16.4 & 0.2 & 1.0 & 64.3 \\
Stratosphere & 0.2 & 3.8 & 10.8 & 1.9 & 0.2 & 16.9 \\
Whole column & 33.6 & 166.3 & 87.2 & 7.2 & 11.2 & 305.6 \\
Cloud & 19.6 & 1.2 & 3.4 & 3.9 & 0.3 & 28.4 \\
Column + cloud & 53.2 & 167.6 & 90.6 & 11.1 & 11.5 & 334.0 \\
\hline
\end{tabular}


the gases. In fact, the most noticeable cloud forcing on DLR comes from the stormy regions in the middle and high latitudes and the strongest tropical cloud forcing emerges in the subsidence regions: for example, the oceanic regions offshore to Peru, where low-level stratiform clouds dominate the scene. As cloud forcing mostly exists in the window region (roughly $800-1200 \mathrm{~cm}^{-1}$ in which the only major absorbing mechanism is the water vapor continuum; see Fig. 5), this indicates that in the deep tropics water vapor absorption is sufficiently strong even in the window region so that the DLR at the surface is rather insensitive to the existence of clouds. The local maximum of cloud forcing in the offshore subsidence regions indicates that, although low clouds have a weak impact on OLR, they exert strong forcing on the surface energy budget through the DLR. The analysis here suggests that the radiative impacts of clouds of different types can be distinguished and separately measured by using height-dependent longwave radiation measurements.

The stratospheric GHEs of the gases are also worth noting. The stratospheric trapping of the OLR amounts to $4.5 \mathrm{~W} \mathrm{~m}^{-2}$, about $3 \%$ of that by the whole atmospheric column, and is a result of compensating effects of different gases, of which $\mathrm{O}_{3}$ has the greatest individual effect. In contrast, the stratospheric contribution to the DLR amounts to $16.9 \mathrm{~W} \mathrm{~m}^{-2}$, about $5 \%$ of the whole column effect, with substantial contributions of the same sign from $\mathrm{H}_{2} \mathrm{O}, \mathrm{CO}_{2}$, and $\mathrm{O}_{3}$. It is evident from Fig. 5 that contributions of these gases are well separated within the spectrum. If spectral measurements were made available, the radiative impacts of them could be unambiguously attributed. This indicates great potential of such measurements for monitoring stratospheric concentrations of these gases. As shown below, an especially useful application is to pin down the stratospheric water vapor change.

\section{b. Discussion}

Because of the critical role that radiation energy plays in the climate system, the distribution of radiation quantities is as important as conventional meteorological variables such as temperature and humidity in terms of indicating the quality of a GCM simulation. Due to the lack of global measurements at other levels, model validation and diagnosis have been very much limited to the TOA radiation fields. The all-sky and clearsky OLR at the TOA that are simulated in this experiment are 240.2 and $260.9 \mathrm{~W} \mathrm{~m}^{-2}$, respectively. In comparison, Trenberth et al. (2009) reported $238.5 \mathrm{~W} \mathrm{~m}^{-2}$ with a $3 \%$ uncertainty for the all-sky OLR based on the Clouds and the Earth's Radiant Energy System (CERES) satellite observations during the period 2000-04. Cloud forcing, assessed as the difference between clear-sky and all-sky OLR, is $20.7 \mathrm{~W} \mathrm{~m}^{-2}$. This is noticeably less than the calculation of Kiehl and Trenberth (1997) and the satellite observations, both of which estimate it to be about $30 \mathrm{~W} \mathrm{~m}^{-2}$ [e.g., the Earth Radiation Budget Experiment (ERBE) estimate is $31.3 \mathrm{~W} \mathrm{~m}^{-2}$ (Ramanathan et al. 1989)]. As diagnosed by Huang et al. (2007), the better agreement in the all-sky OLR results from the cloud field tuning in the GCM, which leaves the clear-sky OLR bias that is caused by upper-tropospheric temperature (too cold) and water vapor (too moist) errors unconstrained.

At the surface, the simulated global mean all-sky upwelling and downwelling longwave radiation are 396.3 and $334.0 \mathrm{~W} \mathrm{~m}^{-2}$, respectively. While the upwelling radiation is largely controlled by the surface temperature with a relatively small uncertainty due to the uncertainty in surface emissivity, the downwelling radiation (DLR) is strongly influenced by the distributions of greenhouse gases and clouds and is of much greater uncertainty. In comparison, for the all-sky DLR values, Kiehl and Trenberth (1997) calculated $324 \mathrm{~W} \mathrm{~m}^{-2}$; Trenberth et al. (2009) reported $333 \mathrm{~W} \mathrm{~m}^{-2}$ based on various estimates; Kato et al. (2011b), $347 \mathrm{~W} \mathrm{~m}^{-2}$. Stephens et al. (2012) estimated the uncertainty in the surface all-sky DLR to be $10 \mathrm{~W} \mathrm{~m}^{-2}$, despite much greater interdataset discrepancy. The cloud radiative effect, if assessed by the difference between all-sky and clear-sky surface DLR, is simulated to be $28.4 \mathrm{~W} \mathrm{~m}^{-2}$ in this experiment, lying in the range from 24 to $34 \mathrm{~W} \mathrm{~m}^{-2}$ reported by Stephens et al. (2012) based on the cloudbase information actively sounded by CloudSat. On a related note, Kiehl and Trenberth calculated a clear-sky DLR value of $278 \mathrm{~W} \mathrm{~m}^{-2}$, which leads to a cloud forcing of $46 \mathrm{~W} \mathrm{~m}^{-2}$, way out of the range given by Stephens. Note that the large uncertainty in cloud forcing as represented by the different values above appear to be more due to uncertainty in clear-sky than all-sky DLR values. The clear-sky DLR uncertainty, as assessed either by interdataset discrepancy or by the uncertainty provided by individual datasets (Stephens et al. 2012), is no less than the all-sky uncertainty.

Lacking observational constraints, the radiation fluxes simulated at other levels within the atmosphere can only be compared to other simulation results. The net longwave radiation fluxes at the five levels derived in Table 1 qualitatively agree with those presented by Zhang et al. (2004) based on the simulation of the Goddard Institute for Space Studies model. Quantitative comparison between the two studies would be subject to differences in simulation period and in the levels at which the fluxes are reported.

As shown in Fig. 5, the GHE of clouds and gases can be distinguished from their spectral signatures. Cloud 


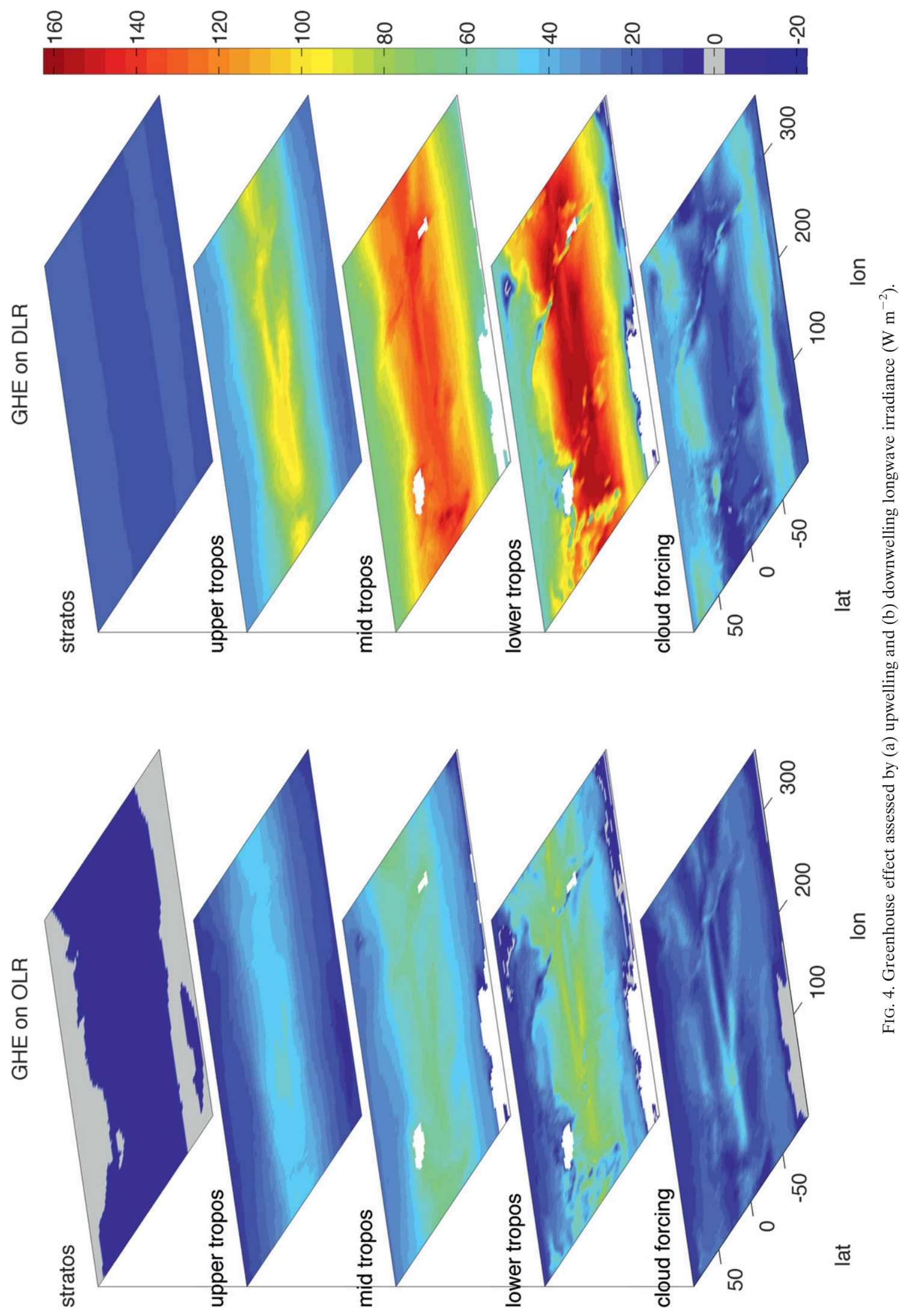



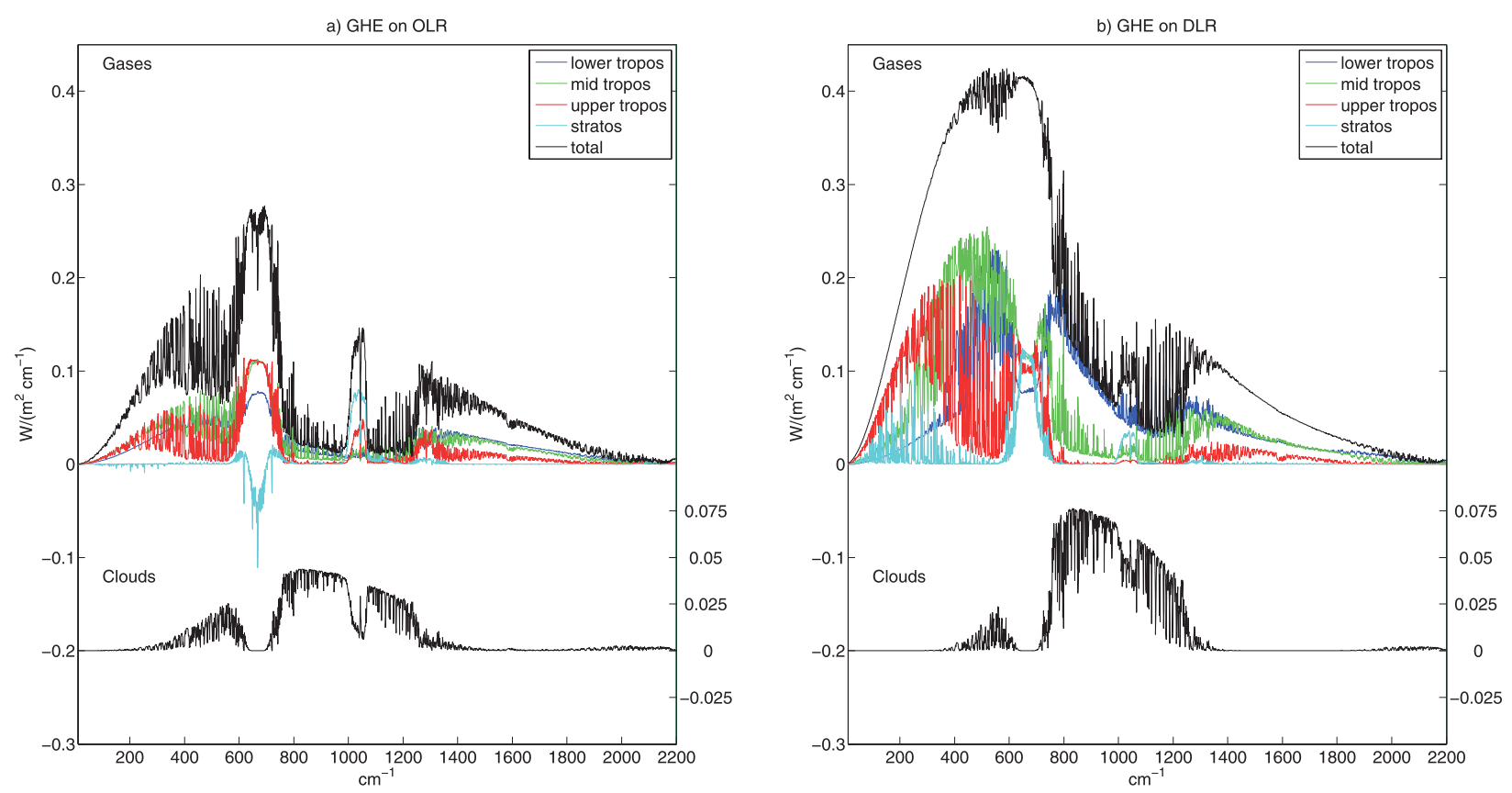

FIG. 5. Spectrally decomposed global multiyear-mean greenhouse effect assessed by (a) upwelling and (b) downwelling longwave radiation.

forcing mainly arises in the window region where the atmosphere is transparent while the GHE of gases lie in their respective absorption bands. This provides the basis for fingerprinting the impacts on the TOA energy budget by these different contributing factors (Huang et al. 2010a). Although the spectral breakdown as in Tables 2 and 3 is only a rough estimate of the individual contribution by the gases as their absorption lines overlap substantially in some spectral regions, this breakdown provides a first-order estimate of the GHE of these gases and resembles the results obtained through more sophisticated calculations [e.g., Kiehl and Trenberth (1997) obtained an estimate by suppressing the absorption of the gases, one at a time, in radiative transfer calculations]. As spectral radiation is a directly measurable quantity, this provides a straightforward way independent of modeling for diagnosing the greenhouse effects of radiative gases and clouds, which can then be used for validating climate models. Huang et al. (2008) is a development along this line, making use of spectrally decomposed OLR measured at the TOA in particular.

\section{Trends}

\section{a. Simulation results}

\section{1) UPWELLING RADIATION}

Figure 6 shows the time series of the anomalies (relative to year 1980) in global annual-mean all-sky OLR and DLR at the five vertical levels. One important aspect of the ongoing climate change is that, while the upwelling radiation fluxes emerging at the surface and at the levels in the troposphere (at 700, 400, and $100 \mathrm{hPa}$ ) significantly increase with time, the OLR at the TOA does not (also see the linear trends compared to associated uncertainties in Table 4). Differencing the trends at consecutive levels discloses that the change in greenhouse effect mainly occurs in the upper troposphere and in the stratosphere. The spectral breakdown of the total OLR change at the five vertical levels (see Fig. 7) elucidates two compensating mechanisms that limit the OLR change at the TOA. First, the increase of OLR due to surface and tropospheric warming is compensated by the decrease of OLR due to stratospheric cooling. Second, there is a compensation between the tropospheric temperature (warming) and opacity effects (increased atmospheric opacity due to increase in greenhouse gas concentration). From the surface up to $100 \mathrm{hPa}$, spectral changes are generally positive across the spectrum, which mainly results from the warming of the surface and the troposphere. The opacity effect modulates the temperature effect and this is evident, for example, from the dips in the $\mathrm{CO}_{2}\left(670 \mathrm{~cm}^{-1}\right)$ and the $\mathrm{O}_{3}$ bands $\left(1050 \mathrm{~cm}^{-1}\right)$ at $100 \mathrm{hPa}$. As the $\mathrm{CO}_{2}$ band is saturated in the lower and middle troposphere, the dip in the $\mathrm{CO}_{2}$ band shows up only at the $100-\mathrm{hPa}$ level. In contrast, the $\mathrm{O}_{3}$ band is not saturated - this dip progressively deepens from the surface to $100 \mathrm{hPa}$. The temperature warming 


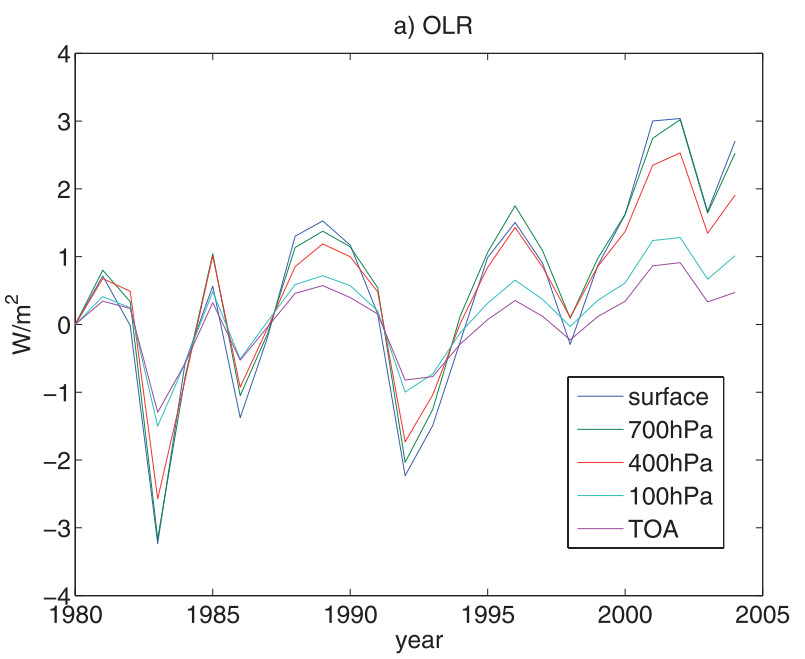

b) DLR

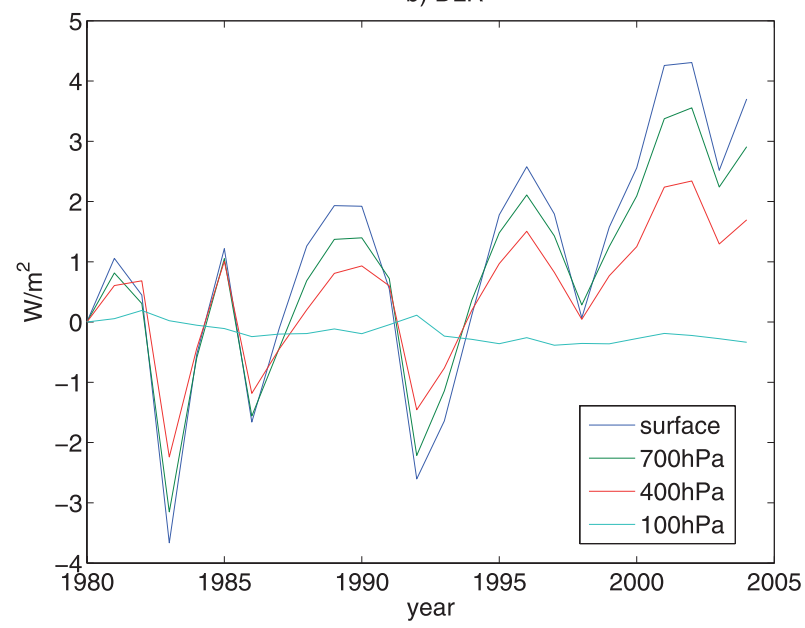

FIG. 6. Time series of the global annual-mean (a) upwelling and

(b) downwelling longwave radiation anomalies $\left(\mathrm{W} \mathrm{m}^{-2}\right)$.

effect wins the competition against the opacity effect so that at $100 \mathrm{hPa}$ the spectral changes remain generally positive. The negative spectral changes at the TOA occur mainly in the $\mathrm{CO}_{2}$ band, and this must be attributed to stratospheric cooling in that the opacity effect would demand changes of opposite sign given the positive temperature lapse rate in the stratosphere. In fact, as water vapor and $\mathrm{CO}_{2}$ both increase in the stratosphere in this simulation, the negative spectral changes caused by stratospheric cooling have been partially offset by the stratospheric opacity effect. Interestingly, the temperature effect of the troposphere (warming) and that of the stratosphere (cooling), after both being offset by the opacity effect, become comparable in magnitude and the compensation between them results in a nearly conserved total OLR.

As noted by Huang and Ramaswamy (2009) for the TOA OLR spectra, the linear trends in the all-sky OLR
TABLE 4. Linear trend and associated uncertainty $(1 \sigma)$ in global multiyear-mean upwelling and downwelling radiation fluxes $\left(\mathrm{W} \mathrm{m}^{-2}\right.$ decade $\left.^{-1}\right)$.

\begin{tabular}{lcccr}
\hline \hline & $R^{+}$ & \multicolumn{1}{c}{$R^{-}$} & $R_{\text {clear }}^{+}$ & \multicolumn{1}{c}{$R_{\text {clear }}^{-}$} \\
\hline Surface & $1.2 \pm 0.7$ & $1.5 \pm 0.8$ & $1.2 \pm 0.7$ & $1.7 \pm 0.9$ \\
$700 \mathrm{hPa}$ & $1.2 \pm 0.7$ & $1.4 \pm 0.7$ & $1.1 \pm 0.6$ & $1.4 \pm 0.7$ \\
$400 \mathrm{hPa}$ & $1.0 \pm 0.5$ & $0.5 \pm 0.5$ & $0.9 \pm 0.5$ & $0.9 \pm 0.4$ \\
$100 \mathrm{hPa}$ & $0.5 \pm 0.3$ & $-0.2 \pm 0.1$ & $0.5 \pm 0.3$ & $-0.2 \pm 0.1$ \\
TOA & $0.3 \pm 0.3$ & - & $0.3 \pm 0.3$ & - \\
\hline
\end{tabular}

and DLR spectra at other vertical levels simulated from this CM2 experiment also resemble those in the clearsky case (not shown here). This indicates insignificant change in cloud forcing.

One application of the OLR spectra is to use them to monitor climate change. This rigorous OSSE verifies the detectability of climate change signals in the OLR spectrum as assessed by the subsampling experiment of Huang and Ramaswamy (2009). Although the total OLR energy is largely conserved, Fig. 8 shows that spectral change signals are significant against the noise due to internal variability (essentially that at the interannual scale in this 25-yr time series). The most detectable secular trend signals appear in the $\mathrm{CO}_{2}$ band and the time that it takes to see these radiance changes is much less than 12 years, which is about the time to detect an equally statistically significant trend in the global annual-mean surface temperature during the same period. Except for a few water vapor lines, these are the only signals that are detectable within 10 years. The signals in the $\mathrm{CO}_{2}$ band are, indeed, the only significant ones that appear in the nearly $10 \mathrm{yr}$ AIRS radiance record (H. H. Aumann 2012, personal communication). Note the discussions on climate change signal detection here and below are made with regard to (nadir) radiance, a directly measurable quantity, rather than irradiance, which is used for the energetic discussions above. The time to detection estimate in Fig. 8 ignores instrument noise but only compares the linear trend signal to the noise due to natural variability.

If absolute radiometric accuracy, as opposed to just an instrument's stability (of systematic error), in radiance measurements can be assured as proposed by the Climate Absolute Radiance and Refractivity Observatory (CLARREO) project (Wielicki et al. 2012, manuscript submitted to Bull. Amer. Meteor. Soc.), it only becomes a matter of time for any secular climate trend signal, no matter how small it is, to emerge above the natural variability and measurement uncertainty. Assuming that the natural-variability-induced uncertainty and the measurement uncertainty are uncorrelated, the time to detection of significant radiance signals can be estimated by the Weatherhead formula: 

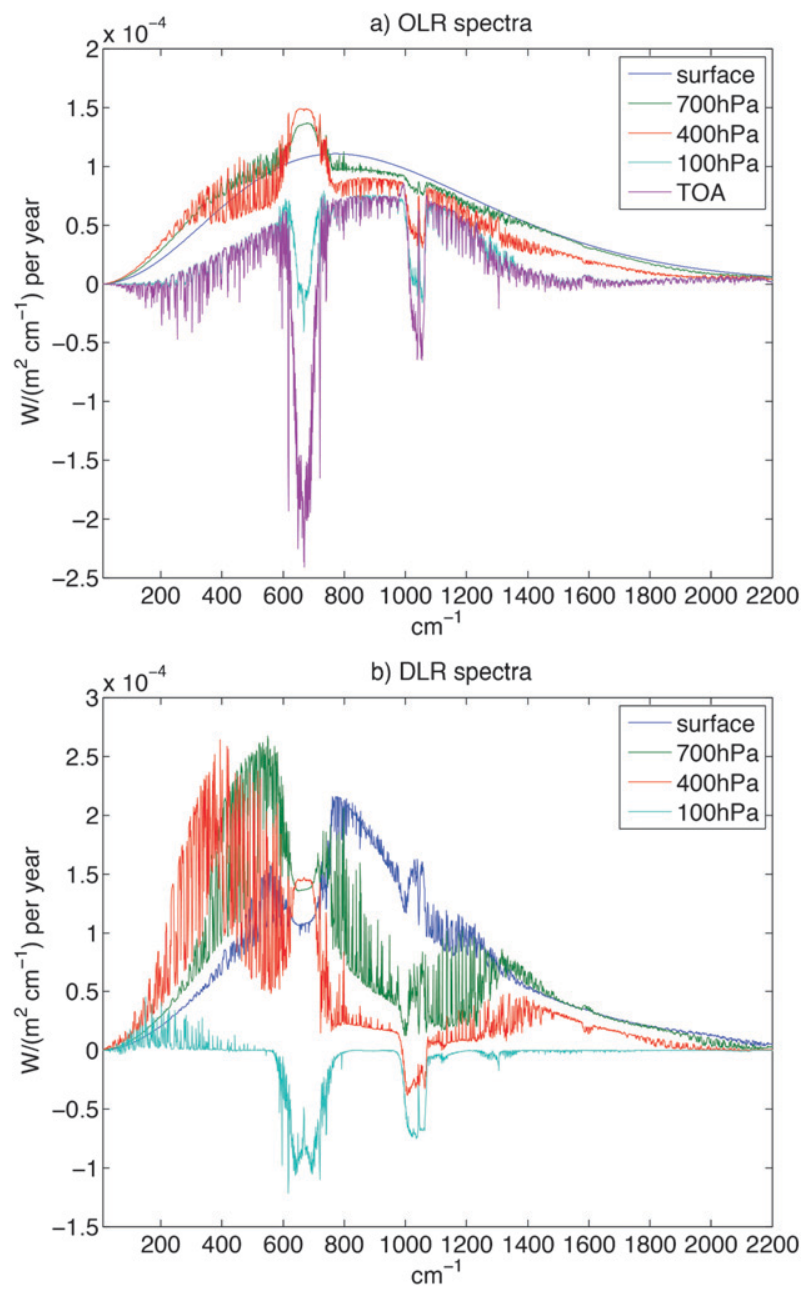

FIG. 7. Linear trends in (a) upwelling and (b) downwelling longwave radiation spectra.

$$
n^{*} \approx\left(\frac{3.3 \sigma_{N}}{\left|\omega_{o}\right|} \frac{1+\phi}{1-\phi}\right)^{2 / 3}\left(1+\frac{\sigma_{m}^{2}}{\sigma_{N}^{2}}\right)^{1 / 3}
$$

Adopting the notations of Weatherhead et al. (1998), here $n^{*}$ is the time to detection of a trend signal with a probability of $90 \% ;\left|\omega_{o}\right|$ is the magnitude of the linear trend in the radiance time series; $\sigma_{N}$ is the naturalvariability-induced uncertainty, in radiance unit, estimated by the standard deviation of the time series; $\sigma_{m}$ is the measurement uncertainty, expressed in the same radiance unit as $\sigma_{N} ; \phi$ is the autocorrelation in the firstorder autoregressive (AR1) process in the time series.

Based on the above formula, Fig. 9 shows how radiometric accuracy may impact the time to detection of climate change using OLR nadir spectra. While the detection time in the $\mathrm{CO}_{2}$ band is insensitive to the uncertainty up to $0.5 \mathrm{~K}$ in radiance measurement, the

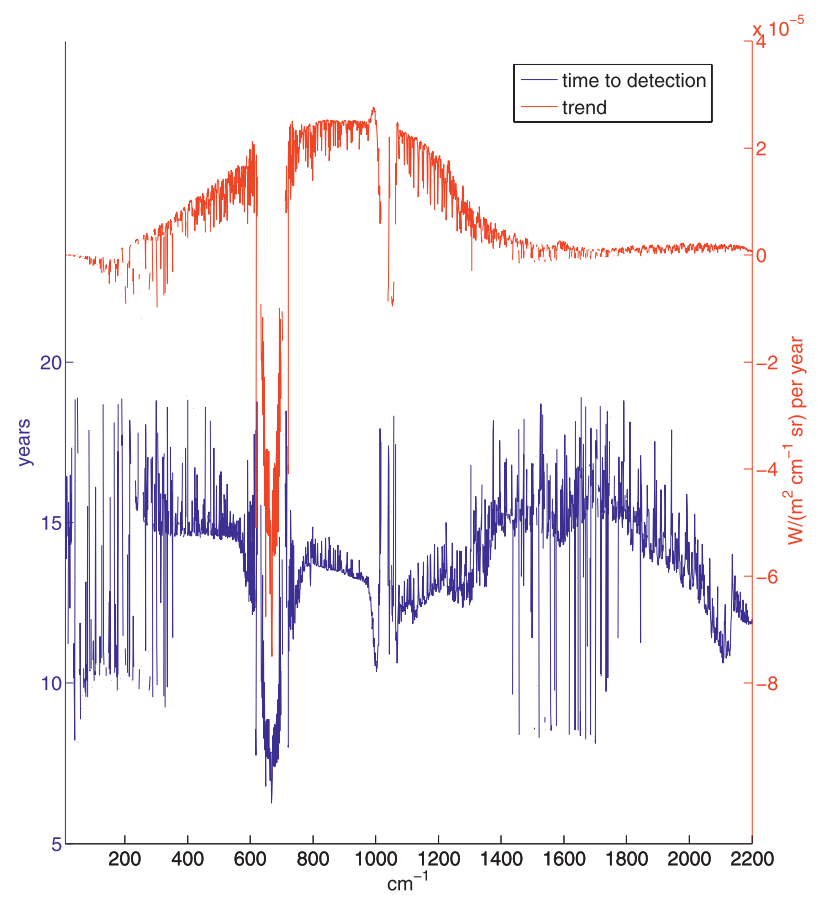

FIG. 8. Linear trends in the TOA OLR nadir spectrum and the time to detection with a $90 \%$ probability.

detection time in the window region and in the water vapor bands may be strongly impacted. As the time series here is only $25 \mathrm{yr}$ long, any $n^{*}$ estimate close to 25 years needs to be treated with caution. When radiance measurement uncertainty is greater than $0.25 \mathrm{~K}$, it would take nearly twice the amount of time (more than 20 as opposed to 12 years) to detect global warming through the radiances in the window region (between 800 and $1250 \mathrm{~cm}^{-1}$ except the $\mathrm{O}_{3}$ band around $1050 \mathrm{~cm}^{-1}$ ). Changes in the water vapor vibration-rotational band (around $1600 \mathrm{~cm}^{-1}$ ) are so delicate that measurement uncertainty as low as $0.1 \mathrm{~K}$ could inhibit the detection of radiance change in this band.

\section{2) DownWELling RADiATION}

The compensation between the temperature and opacity effects does not occur in the tropospheric downwelling radiation. The two effects actually both increase DLR in the troposphere, which renders very noticeable changes at the surface, $700 \mathrm{hPa}$, and $400 \mathrm{hPa}$ (Table 4). Because of the opacity effect (increase in atmospheric emissivity), the spectral lines exhibit super-Planck behavior: that is, radiance change being greater than what temperature change alone can explain according to the Planck function. This phenomenon is most noticeable in unsaturated spectral regions. For instance, peak signals in the water vapor rotational band move from higher to lower wavenumbers, that is, from less absorptive band 
a) OLR

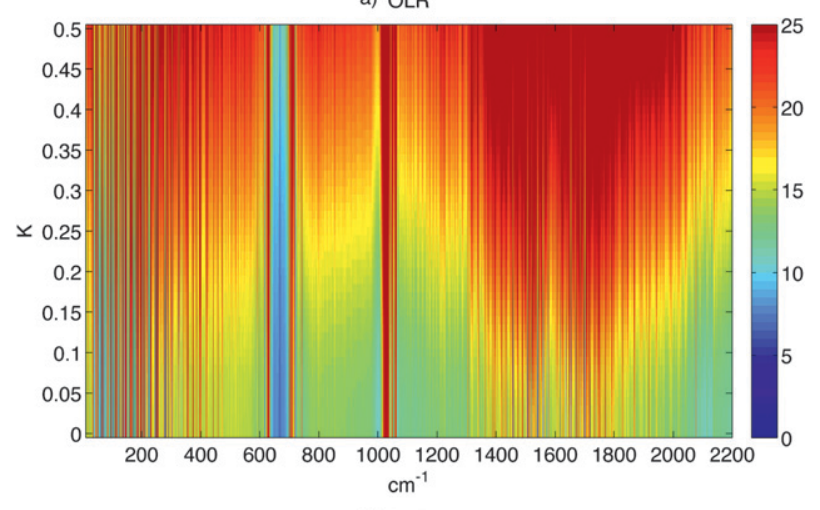

b) DLR

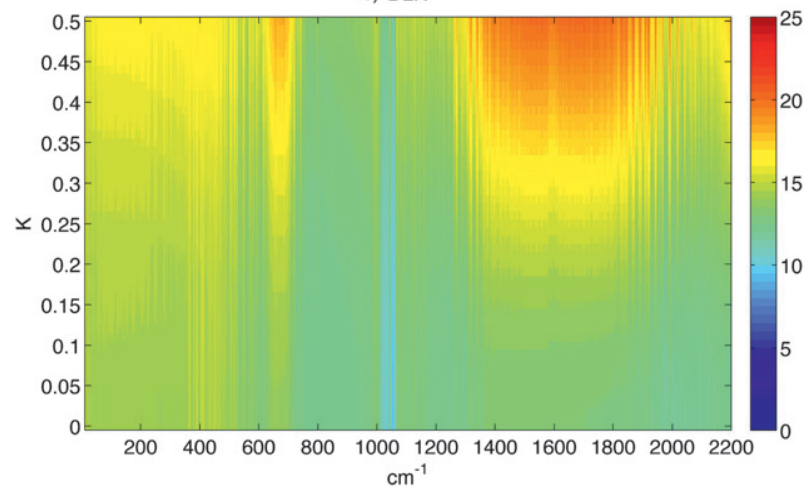

FIG. 9. The time (years) to detection of radiance change, contoured as a function of wavenumber ( $x$ axis) and radiance measurement accuracy ( $y$ axis, brightness temperature): (a) OLR at TOA and (b) DLR at surface.

wing toward more absorptive band center. This means that, unlike the total OLR at the TOA, which is subject to a zero-sum problem, the total DLR at the surface is a readily verifiable aspect of climate change. If climate change happens as hypothesized by the GCM-that is, well-mixed greenhouse gases drive the warming of the troposphere-surface system, possibly enhanced by positive feedbacks (Solomon et al. 2007) - then the DLR must increase. In this regard, it is of interest to see the time required for the DLR irradiance or spectral radiance to disclose climate change. In this OSSE, CM2 simulates a linear trend for the all-sky surface DLR of $1.5 \mathrm{~W} \mathrm{~m}^{-2}$ per decade (Table 4). If ignoring measurement uncertainty, associated detection time with $90 \%$ probability is $12.6 \mathrm{yr}$, which is approximately equal to the time for detecting surface temperature change. Note that, despite the reinforcement of the temperature and opacity effects, the detection time is not shortened. This may be surprising at first sight but is due to the fact that the temperature effect and the water vapor opacity effect are positively correlated in the interannual (natural) variations, which gives rise to a large internal variabilityinduced noise in the time series. As detecting a secular trend signal is essentially to compare it to the noise, the trend signal does not emerge sooner. When spectral radiances are used for trend detection (Fig. 9), the most detectable signals lie in the ozone band, where atmospheric absorption is not saturated and the absorber $\left(\mathrm{O}_{3}\right)$ is not correlated with temperature in interannual variations. Note, however, as the DLR radiance trends are generally greater in magnitude than those of OLR, the detection is much less subjective to measurement inaccuracy.

Different from the other levels, at $100 \mathrm{hPa}$ the DLR decreases because of stratospheric cooling. This is manifest by the spectral changes in the $\mathrm{CO}_{2}\left(560-800 \mathrm{~cm}^{-1}\right)$, $\mathrm{O}_{3}\left(990-1070 \mathrm{~cm}^{-1}\right)$, and $\mathrm{CH}_{4}\left(1250-1350 \mathrm{~cm}^{-1}\right)$ bands (Fig. 7). The positive spectral changes in the far infrared, however, are peculiar, which can only be explained by the moistening of the stratosphere (cf. Fig. 1). As stratospheric absorption is not saturated in the water vapor bands, moistening of the stratosphere increases the emissivity of the stratospheric layer as a whole so that the downwelling radiation to the troposphere increases noticeably. Close examination discloses that the sign of radiance trend is also positive at these wavenumbers in the water vapor vibration-rotational band: 1456,1505 , $1522,1560,1616,1654$, and $1669 \mathrm{~cm}^{-1}$, all of which correspond to strong water vapor lines with line strength greater than $10^{-19} \mathrm{~cm}$ per molecule according to the HITRAN database (Rothman et al. 2009). The positive changes only occur at these strong water vapor lines because at these wavenumbers the weighting function for the downwelling radiances gives more weight to the stratospheric layers adjacent to the tropopause where cooling occurs to a much lesser extent (see Fig. 1) so that the temperature (Planck) effect does not offset the emissivity effect.

\section{b. Discussion}

The temperature effect is known to be a major, if not the only, negative feedback that damps the surface warming induced by the radiative forcing of well-mixed greenhouse gases (Soden et al. 2008). The overall temperature feedback, as shown from the height-dependent spectral analysis above, comprises compensating effects from troposphere and stratosphere, as recognized by Hansen et al. (1981) and others. Although the magnitude of the tropospheric temperature effect far exceeds that of the stratospheric temperature effect, the tropospheric temperature effect is much offset by the tropospheric opacity effect mainly of water vapor and $\mathrm{CO}_{2}$. As tropospheric water vapor and temperature are tightly coupled thermodynamically, this offsetting is somewhat intrinsic. As a consequence, the overall stratospheric effect on the OLR is as important as the overall 
tropospheric effect. This suggests that tropospheric and stratospheric thermal states may be two major factors that govern the first-order change in OLR. There is no known theory that quantitatively relates stratospheric and tropospheric temperature changes; thus, to what extent OLR is conserved under transient climate change is an open question. On the other hand, if OLR conservation holds in nature, there is a strong constraint on surface and tropospheric warming in relation to stratospheric cooling.

The very close clear-sky and all-sky OLR trends in this experiment indicate an insignificant contribution to OLR trend by clouds. It is known, however, that cloud feedback differs across different climate models and, thus, OLR may not be conserved in other models despite the compensations described above. An examination of the A1B experiment of the CMIP3 models (Solomon et al. 2007) does show different behavior of the OLR time series, although the average of the 24 models examined yields an insignificant OLR trend. Not clear, however, is whether cloud feedback is related to (non)conservation of OLR in these models. These questions will be addressed in future investigations.

Another wild card for OLR change is stratospheric water vapor. In contrast to tropospheric water vapor whose first-order change can be predicted by thermodynamical constraint, stratospheric water vapor is not tied to stratospheric temperature but is most likely controlled by stratosphere-troposphere exchange processes (Feuglistaler et al. 2005). As it traps OLR but radiates DLR, stratospheric water vapor warms the surface and troposphere but cools the stratosphere. The longwave radiative effect of water vapor is hypothesized to account for reduced warming of the global-mean surface temperature over the first decade of this century (Solomon et al. 2010): an accompanying effect on stratospheric temperature, however, is not noticed.

On the other hand, IR spectral measurements can provide a means for monitoring stratospheric water vapor. Because of the rareness of it, stratospheric water vapor leaves clear signatures only at those strong water vapor lines. The far-infrared, where lines are generally stronger, thus may be advantageous for tracking the stratospheric water vapor changes. This is particularly true if the downwelling IR spectrum can be measured at the tropopause level. From the contrast between the water vapor rotational band and the $\mathrm{CO}_{2} \nu_{2}$ band (see Fig. 7), stratospheric water vapor change can be unambiguously separated from stratospheric temperature change.

Finally, as the purpose of this OSSE is to explore the information about climate change can be made available by height-dependent IR spectral measurement in theory. Such things as measurement sampling pattern (in both spatial and temporal domains) may affect the experimental verification of the climate change signals. These instrumentation details will be considered in future investigations.

\section{Conclusions}

We conduct a rigorous simulation experiment to inquire what the mean climate state is and what the likely changes of the atmospheric infrared radiation spectra are. Upwelling and downwelling radiation spectra at five vertical levels (surface, $700 \mathrm{hPa}, 400 \mathrm{hPa}, 100 \mathrm{hPa}$, and TOA) are calculated globally from 3-h GCM atmospheric profiles at $2^{\circ} \times 2.5^{\circ}$ horizontal resolution for a 25-yr (1980-2004) period. The multiyear mean and linear trend in the global-mean radiation fluxes and spectra are presented and analyzed in this paper.

Tracing the longwave radiation flux vertically and spectrally renders a dissection of the greenhouse effect of the earth atmosphere and change of the effect due to both climate forcings and feedbacks. It is shown that the greenhouse effect with regard to both upwelling and downwelling radiation fluxes is dominated by atmospheric gas components, especially water vapor, which accounts for about $50 \%$ of the total effect; in comparison, the additional effect by clouds accounts for about $10 \%$. While the lower and middle troposphere contribute to the bulk of the total greenhouse effect, the change of the greenhouse effect mainly results from contributions by the upper troposphere and the stratosphere.

An important aspect of climate change is that the total OLR at the TOA is largely conserved. The conservation results from compensating effects by the temperature effect and the opacity effect and by the contrasting temperature changes in the troposphere and stratosphere. The tightly coupled and compensating tropospheric temperature and greenhouse gas opacity effects reduce the overall tropospheric effect on the OLR to be comparable to the overall effect of the stratosphere. This suggests that the relative strengths of stratospheric cooling and tropospheric warming largely determine the OLR change.

The total OLR energy, however, is redistributed across the infrared spectrum. This more rigorous experiment confirms that spectral measurements provide an advantageous means for monitoring climate change and for dissecting those compensating effects by climate forcing and feedback mechanisms. The most noticeable and the earliest detectable global climate change signal in the OLR spectrum lies in the $\mathrm{CO}_{2}$ absorption bands, which results from stratospheric cooling and the opacity effect of $\mathrm{CO}_{2}$. While this signal is strong and the detection of this change is little affected by instrument accuracy, the 
detection of other spectral signals, for example, those in the water vapor bands and resulting from water vapor and tropospheric temperature feedbacks, is very much subject to radiometric measurement accuracy.

In contrast, the compensating tropospheric temperature and opacity effects that limit the OLR change both increase the DLR at the surface. The time to detection of the DLR change is roughly equal to that of the surface temperature change, which makes DLR a more verifiable aspect of climate change. Height-dependent downwelling spectral measurements can unambiguously disclose water vapor, temperature, and cloud in different vertical portions of the atmosphere. Measuring those strong water vapor absorption lines at the tropopause level can particularly pin down water vapor change in the stratosphere.

Acknowledgments. I thank James Anderson, with whom discussions on the feasibility and potential of airborne IR spectral measurement network stimulated this simulation experiment. I thank Richard Goody, Seiji Kato, Dan Feldman, John Dykema, and Henry Leighton for commenting on an earlier version of this paper and two anonymous reviewers, whose comments also helped improve the quality of this paper.

\section{REFERENCES}

Delworth, T. L., and Coauthors, 2006: GFDL's CM2 global coupled climate models. Part I: Formulation and simulation characteristics. J. Climate, 19, 643-674.

Feldman, D. R., C. A. Algieri, J. R. Ong, and W. D. Collins, 2011: CLARREO shortwave observing system simulation experiments of the twenty-first century: Simulator design and implementation. J. Geophys. Res., 116, D10107, doi:10.1029/2010JD015350.

Fueglistaler, S., M. Bonazzola, P. H. Haynes, and T. Peter, 2005: Stratospheric water vapor predicted from the Lagrangian temperature history of air entering the stratosphere in the tropics. J. Geophys. Res., 110, D08107, doi:10.1029/2004JD005516.

Gero, P. J., and D. D. Turner, 2011: Long-term trends in downwelling spectral infrared radiance over the U.S. southern Great Plains. J. Climate, 24, 4831-4843.

Hansen, J., D. Johnson, A. Lacis, S. Lebedeff, P. Lee, D. Rind, and G. Russell, 1981: Climate impact of increasing atmospheric carbon dioxide. Science, 213, 957-966.

Harries, J. E., H. E. Brindley, P. J. Sagoo, and R. J. Bantges, 2001: Increases in greenhouse forcing inferred from the outgoing longwave radiation spectra of the earth in 1970 and 1997 Nature, 410, 355-357.

Huang, X., W. Yang, N. G. Loeb, and V. Ramaswamy, 2008: Spectrally resolved fluxes derived from collocated AIRS and CERES measurements and their application in model evaluation: Clear sky over the tropical oceans. J. Geophys. Res., 113, D09110, doi:10.1029/2007JD009219.

Huang, Y., and V. Ramaswamy, 2008: Observed and simulated seasonal co-variations of outgoing longwave radiation spectrum and surface temperature. Geophys. Res. Lett., 35, L17803, doi:10.1029/2008GL034859.

- and _ 2009: Evolution and trend of the outgoing longwave radiation spectrum. J. Climate, 22, 4637-4651.

,,-- X. Huang, Q. Fu, and C. Bardeen, 2007: A strict test in climate modeling with spectrally resolved radiances: GCM simulation versus AIRS observations. Geophys. Res. Lett., 34, L24707, doi:10.1029/2007GL031409.

_ , S. Leroy, and J. G. Anderson, 2010a: Determining longwave forcing and feedback using infrared spectra and GNSS radio occultation. J. Climate, 23, 6027-6035.

— — _ P. J. Gero, J. Dykema, and J. Anderson, 2010b: Separation of longwave climate feedbacks from spectral observations. J. Geophys. Res., 115, D07104, doi:10.1029/2009JD012766.

Kato, S., and Coauthors, 2011a: Detection of atmospheric changes in spatially and temporally averaged infrared spectra observed from space. J. Climate, 24, 6392-6407.

_ and surface irradiance computations with CALIPSO-, CloudSat-, and MODIS-derived cloud and aerosol properties. J. Geophys. Res., 116, D19209, doi:10.1029/2011JD016050.

Kiehl, J. T., and K. E. Trenberth, 1997: Earth's annual global mean energy budget. Bull. Amer. Meteor. Soc., 78, 197-208.

Leroy, S., J. Anderson, J. Dykema, and R. Goody, 2008: Testing climate models using thermal infrared spectra. J. Climate, 21, $1863-1875$.

Ramanathan, V., R. D. Cess, E. F. Harrison, P. Minnis, B. R. Barkstrom, E. Ahmad, and D. Hartmann, 1989: Cloud-radiative forcing and climate: Results from the Earth Radiation Budget Experiment. Science, 243, 57-63.

Rothman, L. S., and Coauthors, 2009: The HITRAN 2008 molecular spectroscopic database. J. Quant. Spectrosc. Radiat. Transfer, 110 (9-10), 533-572.

Soden, B. J., I. M. Held, R. Colman, K. M. Shell, J. T. Kiehl, and C. A. Shields, 2008: Quantifying climate feedbacks using radiative kernels. J. Climate, 21, 3504-3520.

Solomon, S., D. Qin, M. Manning, M. Marquis, K. Averyt, M. M. B. Tignor, H. L. Miller Jr., and Z. Chen, Eds., 2007: Climate Change 2007: The Physical Science Basis. Cambridge University Press, 996 pp.

, K. H. Rosenlof, R. W. Portmann, J. S. Daniel, S. M. Davis, T. J. Sanford, and G.-K. Plattner, 2010: Contributions of stratospheric water vapor to decadal changes in the rate of global warming. Science, 327, 1219-1223.

Stephens, G. L., M. Wild, P. W. Stackhouse Jr., T. L' Ecuyer, S. Kato, and D. S. Henderson, 2012: The global character of the flux of downward longwave radiation. J. Climate, 25, 23292340.

Trenberth, K. E., J. T. Fasullo, and J. Kiehl, 2009: Earth's global energy budget. Bull. Amer. Meteor. Soc., 90, 311-323.

Weatherhead, E. C., and Coauthors, 1998: Factors affecting the detection of trends: Statistical considerations and applications to environmental data. J. Geophys. Res., 103 (D14), 17 149-17 161.

Zhang, Y., W. B. Rossow, A. A. Lacis, V. Oinas, and M. I. Mishchenko, 2004: Calculation of radiative fluxes from the surface to top of atmosphere based on ISCCP and other global data sets: Refinements of the radiative transfer model and the input data. J. Geophys. Res., 109, D19105, doi:10.1029/ 2003JD004457. 